\title{
Pelatihan E-Learning untuk Mengintegrasikan TIK dalam Pembelajaran bagi Guru-guru SMA
}

\section{The Training of E-Learning as ICT Integration in Instructional for Senior High School Teachers}

\author{
${ }^{1}$ Ulfia Rahmi, ${ }^{2}$ Abna Hidayati, ${ }^{3}$ Azrul \\ 12 Program Studi Teknologi Pendidikan, Universitas Negeri Padang, Padang \\ 3 Program Studi Ilmu Pendidikan, Universitas Negeri Padang, Padang \\ Korespondensi: Ulfia Rahmi, ulfia@fip.unp.ac.id
}

Naskah Diterima: 16 Juni 2019. Disetujui: 09 Nopember 2019. Disetujui Publikasi: 23 Januari 2020

\begin{abstract}
Schools have supporting facilities for implementing e-learning such as computer laboratories, internet networks, wireless access points, and microtia routers. However, the teachers and the school are not ready from the side of human resources. In other words, the school needs training and workshops for teachers to optimize the use of ICT in learning. The purpose of this activity is to train SMA N 4 Kota Pariaman teachers to prepare e-learning to integrate ICT in the learning process. This activity involved all of the 4 SMA N Pariaman teachers in a number of stages, namely a) introduction to the concepts of e-learning and LMS, b) workshops managing LMS, and c) simulations of e-learning applications that had been prepared by each teacher. The results of this training activity are a) the teachers have been able to design learning materials and activities in e-learning and produce learning material packages, b) the teacher readiness in integrating ICT in learning is increasingly increasing, and c) the school readiness to create smart classes with the application of e-learning.
\end{abstract}

Keywords: e-learning, integrate ICT, LMS, teachers

\begin{abstract}
Abstrak.
Sekolah-sekolah telah memiliki fasilitas pendukung untuk pelaksanaan e-learning seperi laboratorium komputer, jaringan internet, wireless access point, dan microtic router. Namun guru dan pihak sekolah belum siap dari sisi sumberdaya manusia. Sederhananya, pihak sekolah membutuhkan pelatihan dan workshop bagi guru-guru untuk mengoptimalkan penggunaan TIK dalam pembelajaran. Tujuan kegiatan ini adalah melatih guru-guru SMA N 4 Kota Pariaman untuk mempersiapkan e-learning dapat mengintegrasikan TIK dalam proses pembelajaran. Kegiatan ini melibatkan seluruh guru SMA N 4 Kota Pariaman dengan tiga tahap, yaitu a) pengenalan konsep e-learning dan LMS, b) workshop mengelola LMS, dan c) simulasi aplikasi e-learning yang telah disiapkan untuk masing-masing guru. Hasil kegiatan pelatihan ini adalah a) guru telah mampu merancang materi dan aktifitas belajar di e-learning dan menghasilkan paket materi pembelajaran, b) kesiapan guru dalam mengintegrasikan TIK dalam pemebelajaran semangkin meningkat, dan c) kesiapan sekolah untuk menciptakan smart class dengan penerapan e-learning.
\end{abstract}

Kata Kunci: e-learning, integrasi TIK, LMS, guru

\section{Pendahuluan}

Revolusi industri 4.0 tidak saja mempengaruhi bisnis, tetapi juga pembelajaran. Hal ini menyebabkan pembelajaran juga harus mengadaptasi kemajuan perkembangan teknologi informasi di era 4.0. Keterampilan yang mesti dimiliki pada era ini diantaranya adalah a) perilaku dan nilai meliputi inovatif, 
kritis, spiritual; b) pengetahuan meliputi digitalisasi dan komputing, c) kompetensi entrepreneurship, dan d) keterampilan kolaboratif dan teamwork. Keterampilanketerampilan ini dapat diintegrasikan dalam pembelajaran untuk memfamiliarkan keterampilan yang dibutuhkan di era 4.0. Salah satu pengintegrasian keterampilan di era 4.0 dapat diselenggarakan dengan menerapkan pembelajaran terintegrasi teknolgi informasi yang lebih dikenal dengan e-learning pada sekolah. Pembelajaran dengan berbagai tujuan yang akan dicapai perlu mengintengrasikan tren teknologi dalam penyelenggaraannya, salah satunya adalah penyelenggaraan e-learning (Azrul, dkk., 2019).

E-learning merupakan pembelajaran yang menggunakan alat-alat elektronik (Smaldino, Lowther, \& Russell, 2014) yang penggunaannya saat ini mengarah pada penggunaan komputer dan jaringan internet sehingga pendidik dan peserta didik berada dalam sebuah belajar online (Darmawan, 2014). Pemanfaatan komputer dan internet dalam pembelajaran pada sebuah kerangka online learning memiliki manfaat sebagai substitusi, komplemen, dan suplemen (Munir, 2009). Dan untuk mengoptimalkan penggunaannya di lapangan dapat dimulai dengan analisis kebutuhan, desain, pengembangan, implementasi, dan evaluasi (Ghirardini, 2011). Kesuksesan implementasi e-learning tidak terlepas dari desain konten yang disajikan melalui website kepada peserta didik. Konten merupakan faktor yang sangat penting dalam pembelajaran e-learning. Melalui konten e-learning proses pembelajaran bisa kaya informasi, menarik dan menyenangkan. Konten e-learning harus memiliki ketertarikan terhadap kebutuhan belajar siswa sehingga siswa merasa tertantang untuk mengikuti proses pembelajaran.

Penerapan e-learning di sekolah melibatkan semua komponen pembelajaran, diantaranya tujuan, pendidik, peserta didik, materi/strategi/media, dan evaluasi (Prawiradilaga, 2015). Banyak materi yang tersedia di internet yang dapat dimanfaatkan untuk pembelajaran e-learning, namun itu saja tidak cukup. Perlu ada kemampuan guru untuk merancang media pembelajaran yang dapat mengakomodasi kegiatan belajar melalui e-learning, seperti mengoptimalkan konten tersedia dengan beragam aplikasi (Ariyadi, Buntoro, \& Astuti, 2017). SMA Negeri 4 Kota Pariaman telah memiliki fasilitas pendukung untuk pelaksanaan e-learning seperi laboratorium komputer, jaringan internet, wireless access point, dan microtic router. Namun guru dan pihak sekolah membutuhkan pelatihan dan workshop untuk mengoptimalkan fasilitas yang tersedia agar mampu mengintegrasikan TIK dalam pembelajaran.

\section{Metode Pelaksanaan}

Tempat dan Waktu. SMA Negeri 4 Kota Pariaman adalah satu sekolah menengah atas negeri yang berada di wilayah pemerintahan Kota Pariaman. Sekolah ini beralamat di jalan Siti Manggopoh, Naras Hilir, Pariaman Utara, Kota Pariaman, Sumatera Barat. Kegiatan pelaksanaan pelatihan dan workshop diselenggarakan April-Juni 2019.

Khalayak Sasaran. Khalayak sasaran dalam kegiatan pengabdian kepada masyarakat pada pelatihan e-learning adalah seluruh guru-guru SMA 4 Negeri Kota Pariaman, yaitu 65 orang.

Metode Pengabdian. Kegiatan tersebut terdiri dari kegiatan pelatihan dengan pengenalan e-learning, platform LMS yang digunakan dalam e-learning, dan mempersiapkan materi yang akan digunakan dalam e-learning. Kegiatan pelatihan ini diselenggarakan sejak 24 April 2019. Kemudian peserta diberikan waktu selama empat minggu untuk mengumpulkan materi ajar yang dibutuhkan berdasarkan kegiatan pelatihan yang diikuti pada pertemuan pertama. Selama satu bulan ini peserta diberikan kesempatan untuk berkonsultasi dengan tim pengabdian terkait materi yang sedang disiapkan. Selanjutnya pada bulan Juni peserta kembali 
mengikuti workshop. Tuntutan pada pertemuan kedua dan ketiga ini adalah guru menghasilkan e-learning untuk satu kali pertemuan. Tahap berikutnya peserta diberikan waktu selama satu-dua minggu untuk menuntaskan seluruh materi selama satu semester. Kemudian pada pertemuan keempat peserta mensimulasikan pembelajaran berbasis e-learning berdasarkan mata pelajaran yang diampu.

Indikator Keberhasilan. Indikator keberhasilan kegiatan pelatihan e-learning bagi guru-guru SMA N 4 ini adalah setiap guru minimal menghasilkan konten e-learning pada LMS lengkap untuk satu kali pertemuan.

Metode Evaluasi. Guru-guru mensimulasikan hasil desain dan pengembangan $e$ learning di depan tim pengabdian dan kepala sekolah. Hasil simulasi ini diperoleh masukan dari tim dan kepala sekolah untuk menyempurnakan materi/konten $e^{-}$ learning mata pelajaran tertentu. Indikator penilaian evaluasi mencakup kelengkapan materi untuk satu kali pertemuan yaitu, a) pendahuluan, b) variasi konten berupa teks, gambar, grafik, video/animasi, c) ruang dan rancangan keterlibatan siswa-siswa/siswa-guru, d) evaluasi.

\section{A. Pelatihan dan Workshop E-Learning}

Visi misi SMA N 4 Kota Pariaman ini sangat relevan dengan tuntutan era saat ini yaitu pembelajaran abad 21 dan era revolusi 4.0 yang mengintegrasikan perangkat TIK dalam semua kegiatan termasuk dalam pembelajaran. Penerapan TIK dalam pembelajaran dari sisi siswa juga sudah membutuhkan hal tersebut dilaksanakan karena siswa sudah familiar dengan penggunaan perangkat komputer, mobile phone, dan internet namun perlu pembiasaan penggunaan perangkat tersebut untuk hal-hal yang bersifat positif seperti penggunaanna dalam pembelajaran. Alasan kedua bahwa siswa perlu disiapkan agar memiliki kerampilan literasi digital dan literasi informasi agar tidak tersesat selama berinteraksi dengan internet.

Hal ini sejalan dengan keinginan Kepala Sekolah untuk menerapkan $e$ learning ini pada seluruh mata pelajaran. "Siswa-siswa kita perlu dibelajarkan dan dibiasakan dengan penggunaan teknologi dalam pembelajaran karena perkuliahan di perguruan tinggi sudah melaksanakan sistem ini", tutur Kepala Sekolah Desi Susanti, S.Pd. Harapan kedepannya agar SMA N 4 Pariaman ini dapat menjadi model atau sekolah percontohan oleh sekolah lain. Jadi, tidak kita terus yang mengunjungi sekolah lain tapi saatnya kita yang dikunjungi.

Pengawas Sekolah SMA N 4 Pariaman, Bapak Drs. Muhklis, M.Pd. menyetujui harapan kepala sekolah tersebut bahwa ketika program ini berhasil diterapkan di SMA N 4 Pariaman, sekolah ini dapat menjadi contoh untuk sekolah lainnya, tidak saja kota Pariaman tetapi lebih luas se Sumbar bahkan Nasional. Pengawas dalam pembukaan kegiatan pelatihan (Gambar 1) menyampaikan bahwa e-learning ini membuat pembelajaran menjadi lebih menantang, menarik, dan fleksibel. Namun pengawas meminta komitmen disiplin dan budaya belajar dari guru-guru karena teknologi dan pengetahuan berkembang cepat. "Kita sama-sama berjalan maju dengan IPTEKS, tetapi mereka berlari, kita merangkak". Program pelatihan ini sangat bagus karena sebagai salah satu upaya untuk meningkatkan profesional guru-guru.

Pelatihan ini diselenggarakan tiga tahap, tahap pertama pemahaman konsep e-Learning yang disampaikan oleh Dr. Ulfia Rahmi, M.Pd, dan pengenalan Learning Management System (LMS) oleh Azrul, M.Pd (Gambar 2) yang digunakan sebagai media pembelajaran utama. Konsep e-learning pada dasarnya adalah pembelajaran yang dapat dilakukan secara online dimana pengguna dapat mengakses materi dimana saja dan kapan saja. Namun, e-learning yang dimaksud pada pelatihan ini 


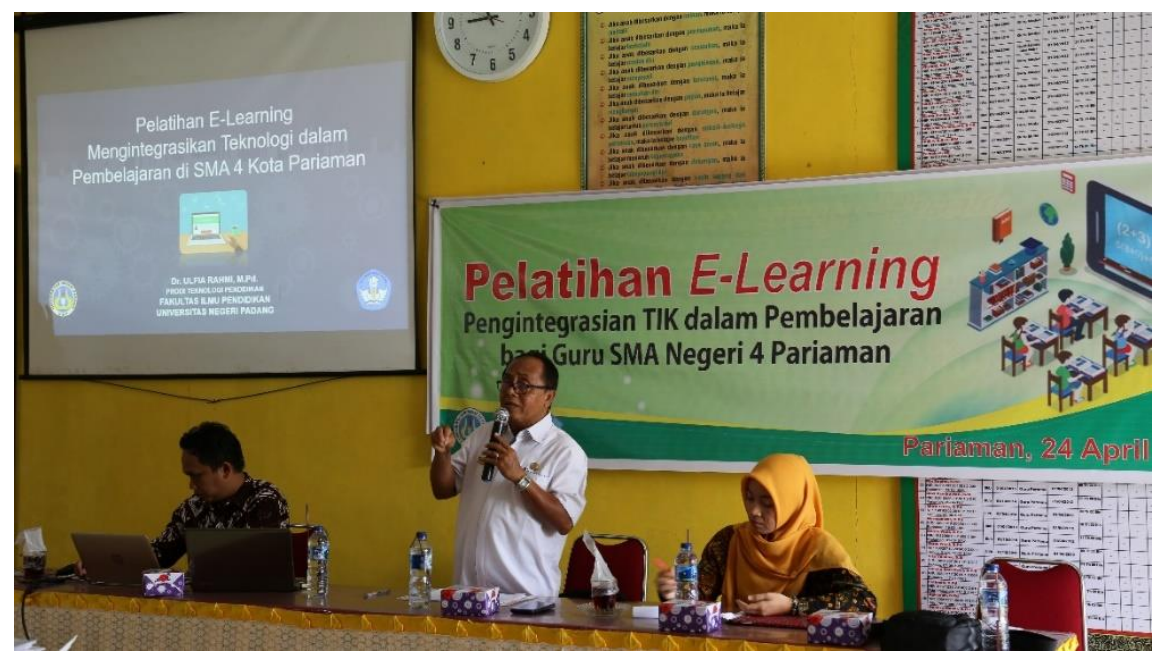

Gambar 1. Pembukaan kegiatan pelatihan oleh Pengawas Sekolah

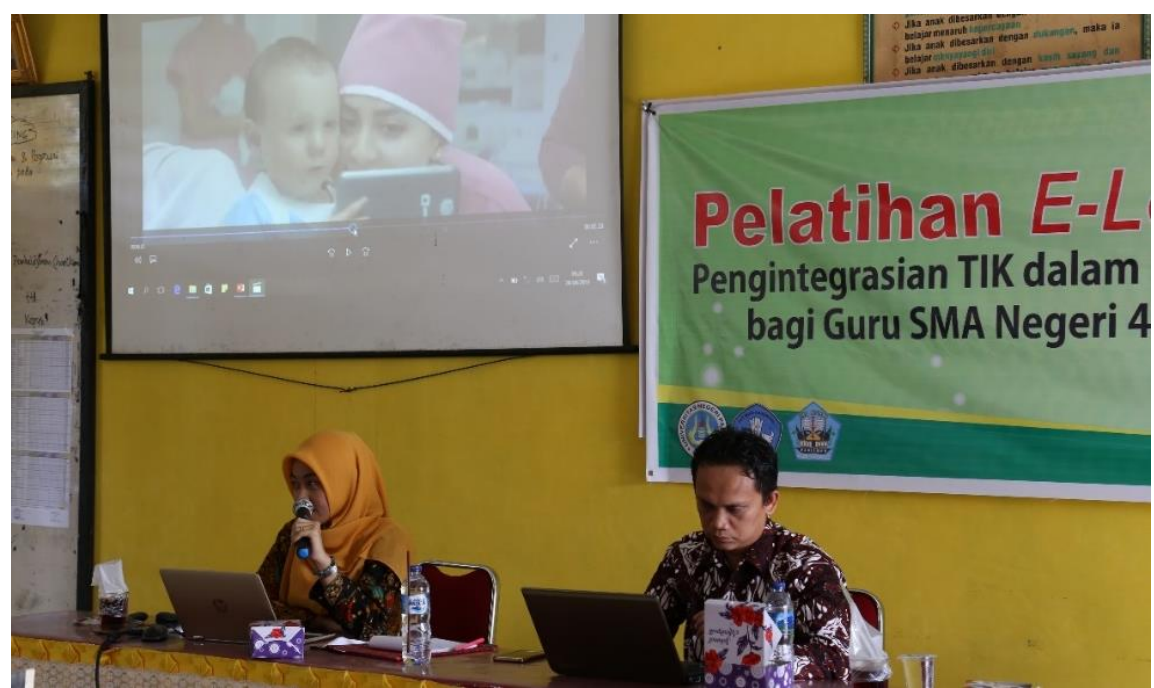

Gambar 2. Penyajian materi dari narasumber

diterapkan dengan sistem blended learning, yaitu kombinasi tatap muka dengan online learning (Bersin, 2004; Watson, 2008). Blended learning juga telah menjadi kajian tim pengabdian dalam beberapa penelitian, seperti daya serap materi melalui blended learning (Hidayati, Bentri, \& Rahmi, 2015), desain pesan dalam blended learning (Rahmi, 2016), blogfolio dalam blended learning (Rahmi, Syafril, \& Azman, 2017), dan evaluasi blended learning (Bentri, Rahmi, \& Hidayati, 2018).

Sistem ini dinilai sangat relevan dengan SMA N 4 Kota Pariaman karena siswa memang setiap hari datang ke sekolah. Jadi, pemanfaatan e-learning berfungsi sebagai komplemen dalam pelajaran yang diselenggarakan di sekolah. Siswa akan belajar di kelas masing-masing seperti biasa namun akan diintegrasikan dengan penerapan e-learning. Sedangkan LMS, merupakan media komunikasi guru dengan siswa selama menerapkan e-learning. Guru-guru dikenalkan bagaimana sistem kerja LMS, fitur-fitur yang tersedia, dan langkah menggunakan LMS tersebut(Gambar 3). Guru juga diberikan contoh materi-materi dan kegiatankegiatan yang telah berlangsung selama menggunakan LMS e-learning ini dalam mata pelajaran Biologi yang sudah diselenggarakan dalam penelitian sebelumnya di SMA N 4 Kota Pariaman. Setelah pelatihan tahap pertama, guru mempersiapkan materi pelajaran menjadi materi digital yang akan di upload ke e-learning. Tim pengabdian menginformasikan kepada guru untuk mempersiapkan konten-konten yang guru upload ke LMS. Terkait konten, guru-guru akan dikenalkan dengan 
format konten (Smaldino et al., 2014) yang dapat mendukung keterlaksanaan dan interaktivitas siswa (Ghirardini, 2011; Mayer, 2009) dengan konten selama pembelajaran berlangsung. Format media yang dapat mengoptimalkan tampilan LMS e-learning yaitu teks, gambar, foto, animasi, audio, dan video.

Kegiatan workshop dilakukan pada tahap kedua. Pada tahap dua ini kegiatan workshop lebih fokus bagaimana cara mengupload dan menjadikan materi pada fitur yang tersedia pada apikasi e-learning. Pada kegiatan kedua ini, guru minimal menyelesaikan satu materi untuk satu kali pertemuan. Kemudian, setelah guru memiliki materi yang akan diupload, pertemuan berikutnya guru dibimbing melalui workshop. Guru langsung bekerja mengupload materi yang telah dikumpulkan untuk materi tertentu (Gambar 4). Minimal dalam satu kali pertemuan guru mampu menyelesaikan materi e-learning untuk satu kali pertemuan. Guru diberikan waktu untuk mendesain dan mengembangkan konten e-learning untuk satu mata pelajaran selama satu tahun ajaran.

Tahap ketiga, guru mensimulasikan hasil rancangan e-learning kepada tim pengabdi, kepala sekolah, dan teman sejawat untuk mendapatkan masukan. Dari simulasi ini diperoleh masukan dari tim dan kepala sekolah untuk menyempurnakan materi/konten e-learning mata pelajaran tertentu.

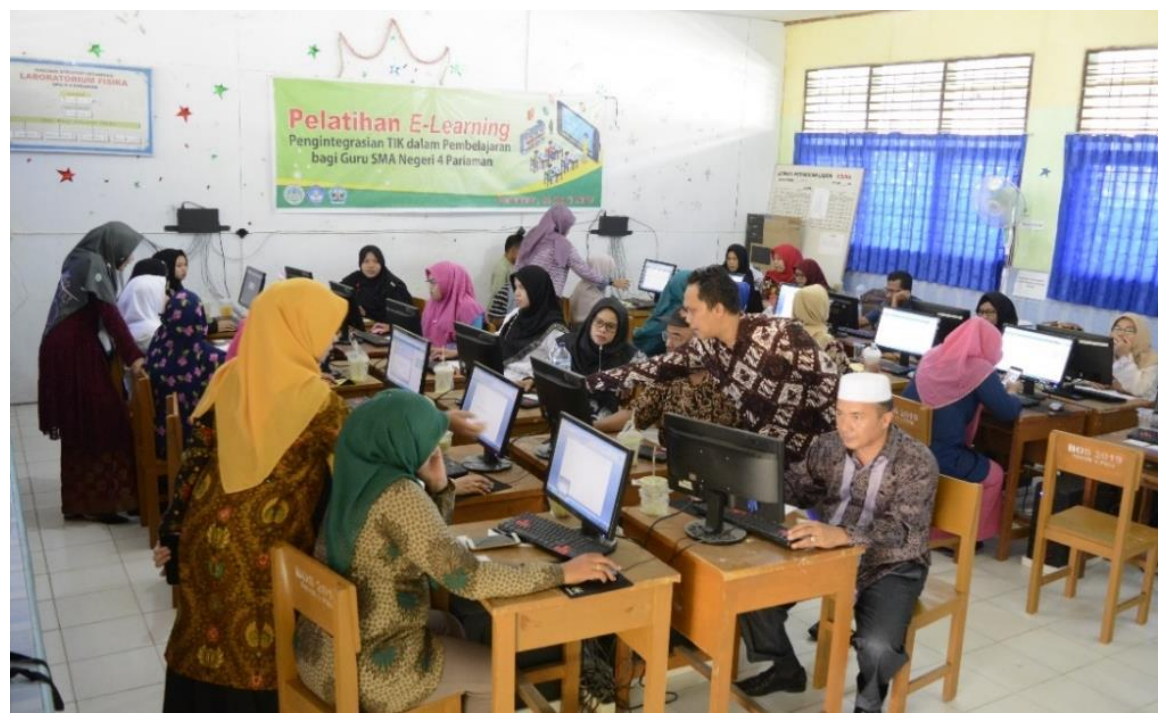

Gambar 3. Suasana bimbingan dari fasilitator bagi guru-guru

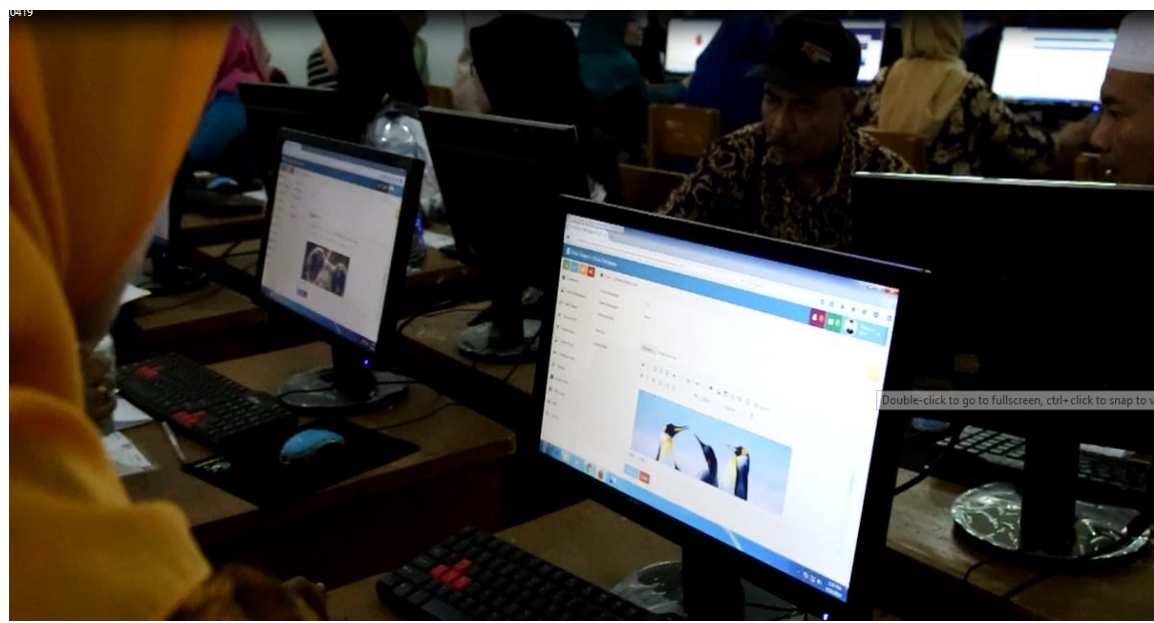

Gambar 4. Guru-guru berlatih menginput konten e-learning ke LMS 


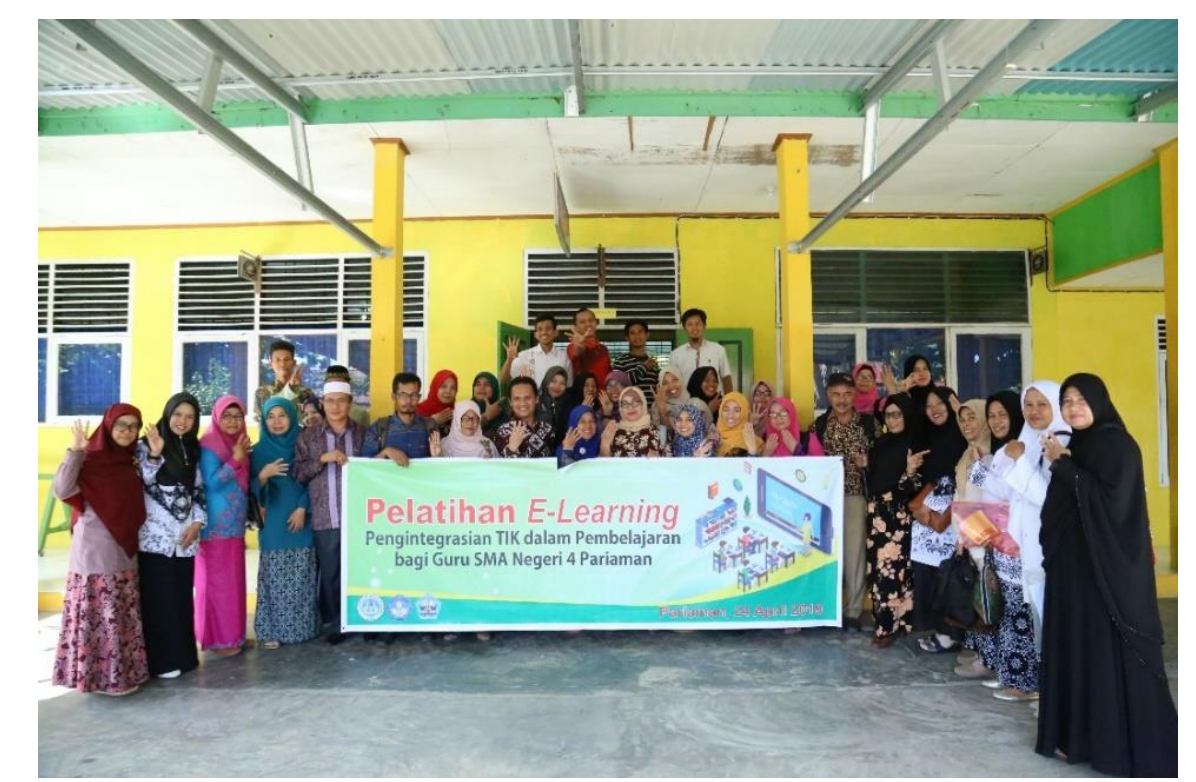

Gambar 5. Peserta pelatihan e-learning berfoto di akhir kegiatan

\section{B. Keberhasilan Kegiatan}

Indikator keberhasilan pada kegiatan pelatihan dan workshop ini adalah kemampuan guru merancang e-learning untuk satu kali pertemuan. Berdasarkan hasil kegiatan pelatihan ini adalah guru telah berhasil membuat paket materi utuh untuk satu kali pertemuan untuk seluruh mata pelajaran kelas X SMA. Paket materi berupa variasi konten e-learning terdiri dari konten teks, gambar dan juga video yang akan diakses oleh siswa melalui akun masing-masing. Pada gambar 6, salah satu guru SMA N 4 Kota Pariaman yang telah berhasil melengkapi materi maju untuk mempresentasikan hasil workshopnya (Gambar 6). Simulasi LMS yang telah dilengkapi dengan konten diikuti oleh guru-guru lain yang sudah memenuhi minimal satu materi untuk satu pertemuan. Pada saat melakukan simulasi, simulator mendapatkan masukan dari teman sejawat dan tim pengabdi untuk menyempurnakan tampilan materi pada LMS.

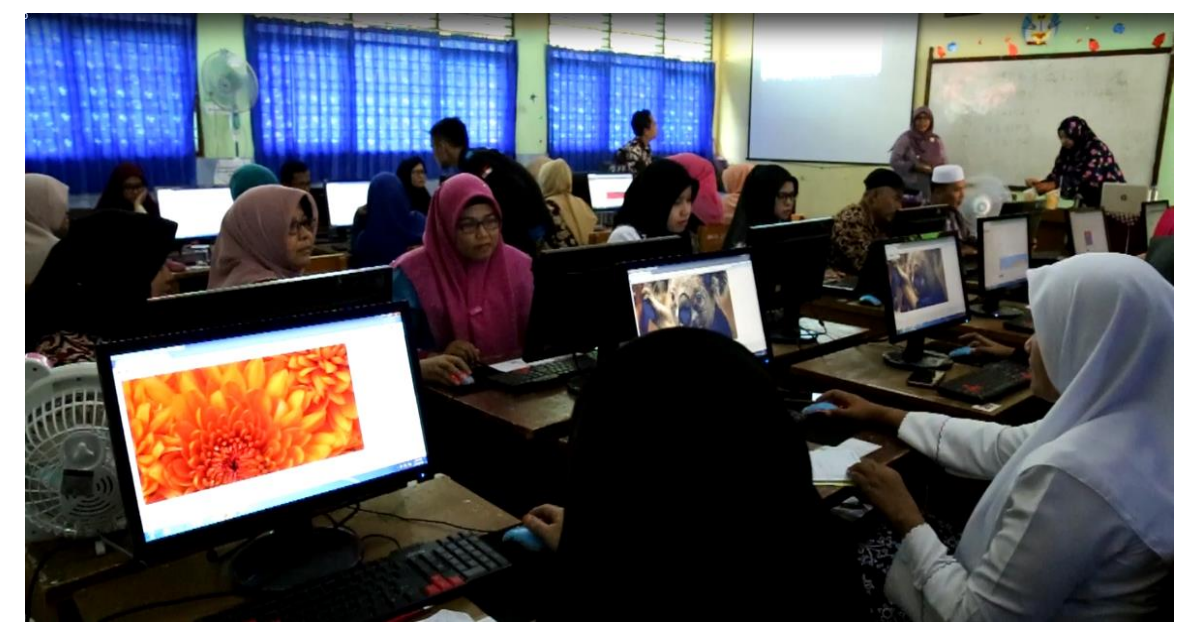

Gambar 6. Salah satu guru mensimulasikan konten e-earning yang telah diinput

Sesuai dengan tema pelatihan yang dilakukan adalah pengintegrasian TIK dalam pembelajaran, kegiatan ini telah membawa pengaruh terhadap kesiapan guru dalam menggunakan perangkat teknologi yang sebenarnya tidak bisa terlepas dari kegiatan sehari-hari para guru. Pelatihan e-learning memberikan kepercayaan diri para guru untuk bisa menggunakan TIK dalam pembelajaran. Penilaian 
capaian keberhasilan peserta pelatihan adalah memenuhi materi satu kali pertemuan. Capaian kinerja peserta dinilai berdasarkan indikator yaitu pendahuluan, variasi konten, rancangan keterlibatan siswa, dan penilaian aktivitas belajar. Ketiga indikator ini tercapai oleh sebagian besar peserta.

\section{Kesimpulan}

Guru telah mampu merancang materi dan aktifitas belajar di e-learning dan menghasilkan paket materi pembelajaran. Guru siap mengintegrasikan TIK dalam pemebelajaran semangkin meningkat. Sekolah siap untuk menciptakan smart class dengan penerapan e-learning. Diharapkan guru-guru dapat melanjutkan pengembangan konten e-learning dan menyempurnakan materi yang telah ada.

\section{Ucapan Terima Kasih}

Tim pengabdian mengucapkan terima kasih kepada Rektor dan Ketua LP2M UNP yang telah memberikan dukungan dana bagian kegiatan ini melalui Program Pengabdian kepada Masyarakat Skim Program Kemitraan Masyarakat (PKM) tahun 2019. Tim pengabdi juga mengucapkan terima kasih kepada SMA 4 N Kota Pariaman sebagai mitra, khususnya kepala sekolah yang telah menyambut dan menyokong dengan maksimal program e-learning ini untuk sekolah yang dipimpinnya.

\section{Referensi}

Ariyadi, D., Buntoro, G. A., \& Astuti, I.P. (2017). Pelatihan Media E-Learning Quipper bagi Guru di MAN1 Ponorogo. Panrita Abdi Jurnal, 1(2), 135 - 140.

Azrul, A., Rukun, K., \& Darmansyah. (2019). The Relationship Between Internal Locus Control And Students Perception Toward E-Learning in Biology Subject in Senior High School. International Journal of Progressive Sciences and Technologies, 14(2), 262-266. Retrieved from http://www.ijpsat.ijshtjournals.org/index.php/ijpsat/article/view/899

Bentri, A., Rahmi, U., \& Hidayati, A. (2018). Model Instrumen Penilaian Blended Learning Di Perguruan Tinggi. Padang.

Bersin, J. (2004). The Blended Learning Book. San Francisco: John Wiley \& Sons, Inc.

Darmawan, D. (2014). Pengembangan E-Learning Teori dan Desain. Bandung: PT Remaja Rosdakarya.

Ghirardini, B. (2011). E-learning methodologies: A guide for designing and developing e-learning courses. Food and Agriculture Organization of the United Nations.

Hidayati, A., Bentri, A., \& Rahmi, U. (2015). Daya Serap Mahasiswa terhadap Materi dengan Penerapan Blended Learning di Fakultas Ilmu Pendidikan Universitas Negeri Padang. Padang.

Mayer, R. E. (2009). Multimedia Learning. In Multimedia Learning (2nd ed., Vol. 1). https://doi.org/10.1017/CBO9781107415324.004

Munir. (2009). Pembelajaran Jarak Jauh Berbasis Teknologi Informasi dan Komunikasi. Bandung: ALFABETA.

Prawiradilaga, D. S. (2015). Prinsip desain pembelajaran. Kencana.

Rahmi, U. (2016). Pengembangan Model Desain Pesan Blended Learning. Universitas Negeri Padang.

Rahmi, U., Syafril, \& Azman. (2017). Blogfolios dalam Blended Learning sebagai Sarana dalam Pengembangan Kemampuan Pemrosesan Informasi Mahasiswa di Era Digital pada Program Studi Teknologi Pendidikan FIP UNP. Padang.

Smaldino, S. E., Lowther, D. L., \& Russell, J. D. (2014). Instructional technology and media for learning: Teknologi pembelajaran dan media untuk belajar. Prenada Media. 
Watson, J. (2008). Blended Learning: The Convergence of Online and Face-to-Face Education. Promising Practices in Online Learning. North American Council for Online Learning.

Penulis:

Ulfia Rahmi, Program Studi Teknologi Pendidikan, Fakultas Ilmu Pendidikan, Universitas Negeri Padang, Padang. E-mail: ulfia@fip.unp.ac.id

Abna Hidayati, Program Studi Teknologi Pendidikan, Fakultas Ilmu Pendidikan, Universitas Negeri Padang, Padang. E-mail: abnahidayati@fip.unp.ac.id

Azrul, Program Studi Ilmu Pendidikan, Pascasarjana, Universitas Negeri Padang, Padang. E-mail: azrulmardin@unp.ac.id

Bagaimana men-sitasi artikel ini:

Rahmi, U., Hidayati., A., \& Azrul. (2020). Pelatihan E-Learning untuk Mengintegrasikan TIK dalam Pembelajaran bagi Guru-guru SMA. Jurnal Panrita Abdi, 4(1), 34 - 41. 